\title{
Pemberian Syarat Reflektif Kecepatan Fluida di Batas Anomali Kedalaman dalam Simulasi Persamaan Air Dangkal
}

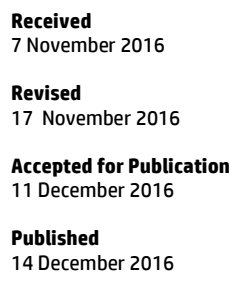

\author{
N. A. Pramono \\ Jurusan Fisika, Fakultas Matematika dan Ilmu Pengetahuan Malang, Universitas Negeri Malang, \\ Indonesia \\ *E-mail: nugroho.adi.fmipa@um.ac.id
}

\begin{abstract}
The simulation of shallow water equation with straight configuration reflective depth anomaly has been performed. This program simulated wave absorber in the beach in order to prevent further abrasion of by sea. This program using modified Navier-Stokes equation and running on Matlab program. The result shows that depth-anomaly reduced the amount on wave amplitude by a significant value.
\end{abstract}

Keywords: Shallow Water Equation, Navier Stokes, Depth Anomaly.

\begin{abstract}
Abstrak
Telah dihasilkan program simulasi persamaan air dangkal dengan pemberian anomali kedalaman yang memiliki sifat reflektif. Program ini mensimulasikan pemecah ombak di pantai. Oleh karena itu dapat digunakan untuk mengurangi abrasi oleh air laut. Persamaan yang digunakan adalah persamaan Navier-Stokes. Kode program ditulis dalam Matlab. Hasil simulasi menunjukkan bahwa pemberian anomali kedalaman dapat mengubah arah gelombang. Pemberian sifat reflektif kecepatan pada anomali kedalaman memberikan pengurangan yang signifikan pada amplitudo gelombang.
\end{abstract}

Kata Kunci: Persamaan air dangkal, Navier-Stokes, anomali kedalaman.

\section{Pendahuluan}

Persamaan Navier-Stokes dapat menjelaskan tentang fluida yang mengalir. Contoh dari dinamika fluida adalah pergerakkan gelombang air laut. Oleh karena itu pergerakan gelombangh air laut dapat dijelaskan dengan menggunakan persamaan Navier-Stokes. Persamaan Navier-Stokes sendiri adalah persamaan yang menjelaskan proses fluida dalam tiga dimensi dengan beberapa penyederhanaan [1].

Simulasi gelombang yang panjang gelombangnya mirip dengan ketinggian air secara kesuluruhan dapat menggunakan air dangkal [1]. Oleh karena itu fluida yang dipilih dalam penelitian ini adalah air dangkal (shallow water) yang secara otomatis pendekatannya menggunakan persamaan air dangkal. Perairan dangkal adalah perairan yang punya batas permukaan (surface) dan batas dasar (bottom) [2].

Penelitian ini telah dilakukan oleh [1-7] dengan membuat variabel awal kedalaman, kecepatan arah $x$ dan arah $y$ masing-masing bernilai $H=1, u=1$, dan $v=0$. Penelitian sebelumnya tentang simulasi persamaan air dangkal dilakukan dengan membuat variasi pada nilai $H$ di beberapa titik yang selanjutnya disebut dengan anomali. Akan tetapi pada penelitian tersebut tidak dilakukan perlakuan khusus terhadap batas anomali. Oleh karena itu anomali hanya berupa sel dengan $H$ bernilai tetap. Sementara tetangganya mengikuti aturan sel normal.

Secara simulasi telah didapatkan hasil bahwa amplitudo gelombang melemah setelah melewati batas anomali. Akan tetapi pelemahan tersebut kurang signifikan karena tidak ada perlakukan khusus pada proses penghitungan di batas anomali, sehingga dianggap seperti titik lain di sistem. Penelitian ini menambahkan syarat reflektif kedalaman dan kecepatan pada anomali sedemikian rupa sehingga sel-sel yang berbatasan dengan sel anomali akan memiliki sifat reflektif baik dalam kecepatan maupun kedalaman sehingga mendekati keadaan sebenarnya, yaitu gelombang air yang menabrak sebuah karang. 


\section{Metode Penelitian}

Penelitian ini merupakan simulasi sistem fisis dengan metode komputasi. Sistem fisis yang dikaji adalah fluida dalam wadah berbentuk kubus dengan ukuran $64 \times 64$ grid dengan kedalaman satu satuan.

Pergerakan fluida dihitung dengan menggunakan persamaan air dangkal yaitu

$$
\begin{gathered}
\frac{\partial h}{\partial t}+\frac{\partial(u h)}{\partial x}+\frac{\partial(v h)}{\partial y}=0 \\
\frac{\partial(u h)}{\partial t}+\frac{\partial\left(u^{2} h+\frac{1}{2} g h^{2}\right)}{\partial x}+\frac{\partial(u v h)}{\partial y}=0 \\
\frac{\partial(v h)}{\partial t}+\frac{\partial(u v h)}{\partial x}+\frac{\partial\left(v^{2} h+\frac{1}{2} g h^{2}\right)}{\partial y}=0
\end{gathered}
$$

Variabel bebas dalam persamaan (1),(2), dan (3) adalah $x, y$, dan $t$. Untuk variabel terikatnya adalah $h$ dan dua dimensi kecepatan $u$ dan $v$. Turunan parsial diperoleh dari komponen variabel di persamaan (1),(2), dan (3) $(\partial t, \partial x, \partial y)$ yang selanjutnya dikelompokkan menjadi vektor dan dituliskan kembali sebagai turunan pertama hiperbolik parsial. Vektor tersebut adalah

$$
\begin{gathered}
U=\left(\begin{array}{c}
h \\
u h \\
v h
\end{array}\right) \\
F(U)=\left(\begin{array}{c}
u h \\
u^{2} h+\frac{1}{2} g h^{2} \\
u v h
\end{array}\right) \\
G(U)=\left(\begin{array}{c}
v h \\
u v h \\
v^{2} h+\frac{1}{2} g h^{2}
\end{array}\right)
\end{gathered}
$$

Persamaan turunan pertama hiperbolik parsial adalah

$$
\frac{\partial U}{\partial t}+\frac{\partial F(U)}{\partial x}+\frac{\partial G(U)}{\partial y}=0
$$

Grid dari sistem fisis yang ditinjau menunjukkan setiap sel memiliki $u, v$ dan $h$ dengan nilai awal nol untuk $u$ dan $v$ dan satu untuk $h$ seperti pada Gambar 1a. Saat sistem diberi gangguan, maka nilai dari $u, v$ dan $h$ tiap sel akan berubah sesuai dengan persamaan (7).

Penyelesaian persamaan turunan parsial hiperbolik adalah dengan metode numerik. Metode ini menggunakan metode Lax-Wendroff. Nilai $u, v$ dan $h$ pada $t+1$ diperoleh dengan mencari nilai antara seperti yang ditunjukkan Gambar.2. Nilai antara titik-titik tersebut diperoleh dengan menggunakan persamaan

$$
U_{i+\frac{1}{2}, j}^{n+\frac{1}{2}}=\frac{1}{2}\left(U_{i+1, j}^{n}+U_{i, j}^{n}\right)-\frac{\Delta t}{2 \Delta x}\left(F_{i+1, j}^{n}-F_{i, j}^{n}\right)
$$

dan

$$
U_{i, j+\frac{1}{2}}^{n+\frac{1}{2}}=\frac{1}{2}\left(U_{i, j+1}^{n}+U_{i, j}^{n}\right)-\frac{\Delta t}{2 \Delta x}\left(G_{i, j+1}^{n}-G_{i, j}^{n}\right)
$$


Dari nilai-nilai antara tersebut dapat dihitung nilai di $t+1$ dengan menggunakan persamaan

$$
U_{i, j}^{n+1}=U_{i, j}^{n}-\frac{\Delta t}{\Delta x}\left(F_{i+\frac{1}{2}, j}^{n+\frac{1}{2}}-F_{i-\frac{1}{2}, j}^{n+\frac{1}{2}}\right)-\frac{\Delta t}{\Delta x}\left(G_{i, j+\frac{1}{2}}^{n+\frac{1}{2}}-G_{i, j-\frac{1}{2}}^{n+\frac{1}{2}}\right)
$$

Sementara bagan alur program simulasi persamaan air dangkal dengan syarat reflektif ditunjukkan Gambar 2. Matrik yang mewakili sistem fisis dibuat di Matlab dan diberi nilai awal dengan kode sebagai berikut:

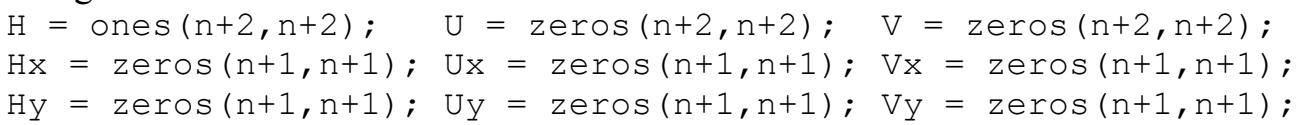

Sementara untuk menyimpan data sel[1,1] selama program berjalan, digunakan perintah berikut:

data=nstep;

dlmwrite ('SB3nStepR.csv', data, 'delimiter' , ', ', '-append' ) ; data $=\mathrm{H}(1,1)$;

dlmwrite ('SB3HR.CSV', data, 'delimiter' , ', ', ' -append' ) ;

Syarat reflektif tepi sistem adalah

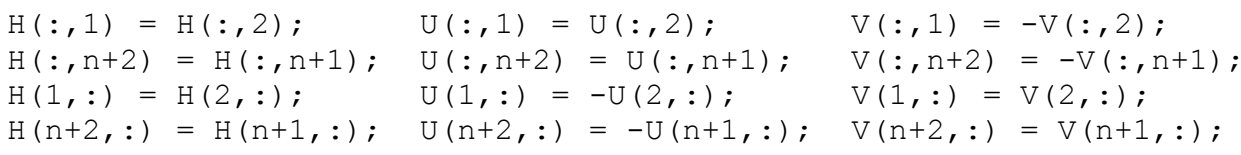

Selanjutnya setengah langkah pertama adalah menghitung nilai-antara pada persamaan (8) yaitu

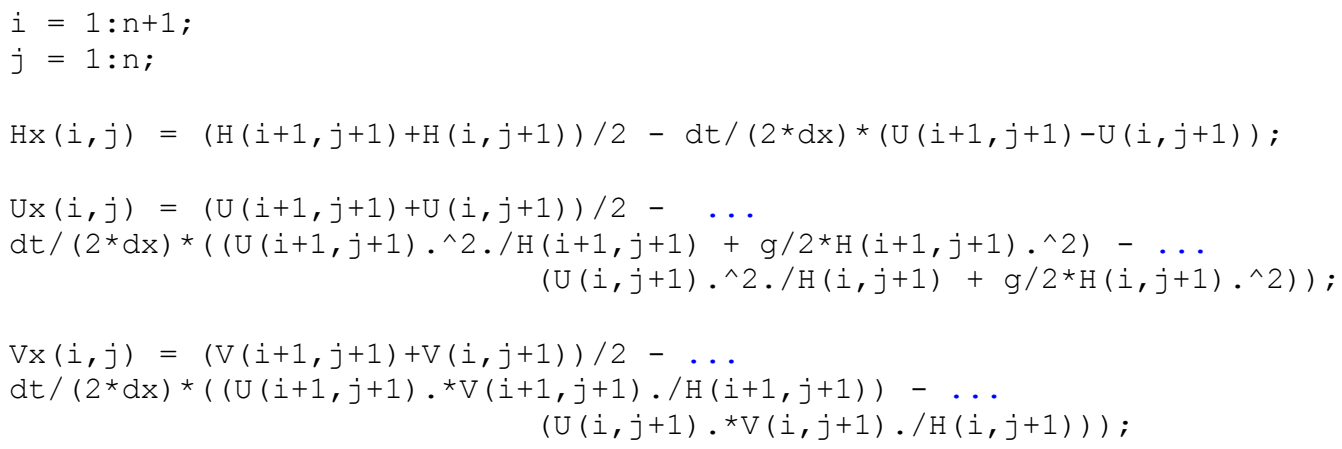

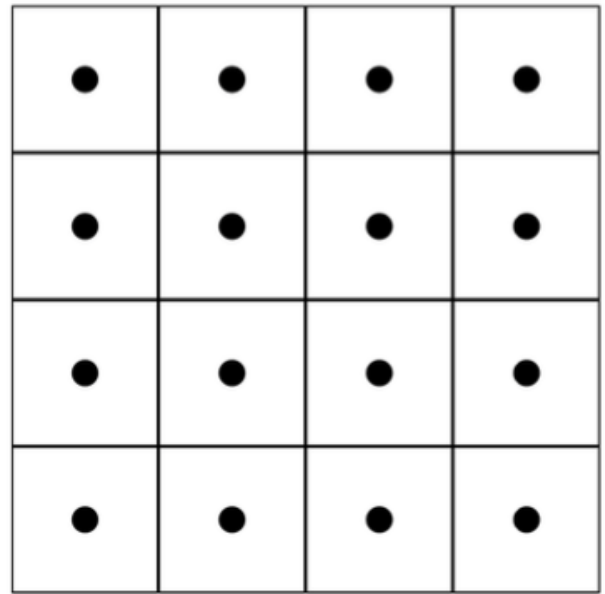

(a)

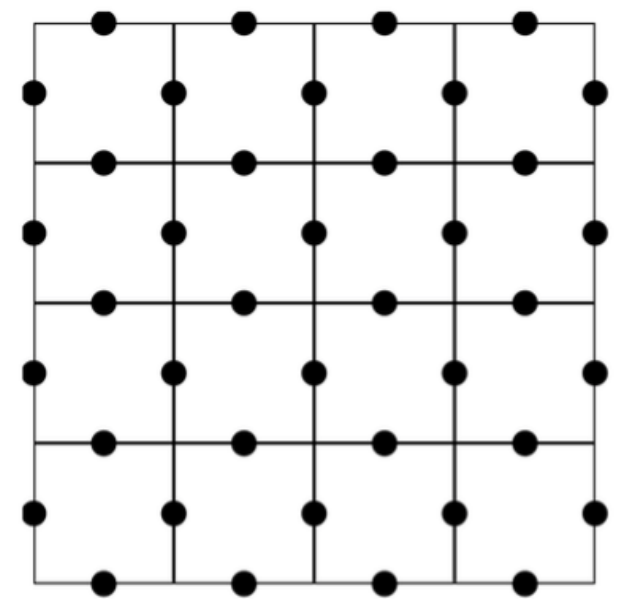

(b)

Gambar 1. (a) Grid dari sistem fisis, (b) Nilai antara untuk menghitung $u, v$, dan $h$ 


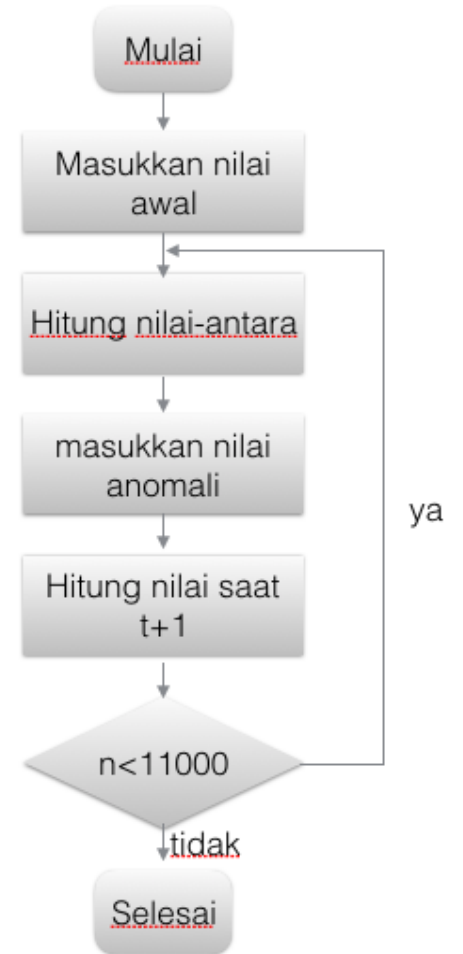

Gambar 2. Bagan alur program simulasi persamaan air dangkal dengan syarat reflektif dan Persamaan (9) yaitu

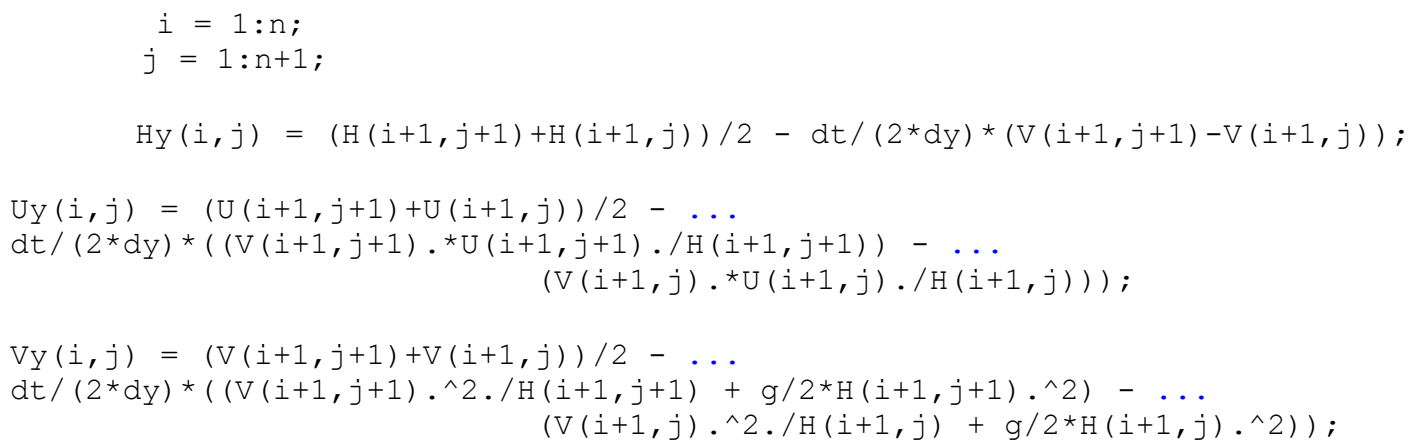

Sementara setengah langkah kedua adalah menghitung nilai di $t+1$ seperti pada Persamaan (10) yaitu

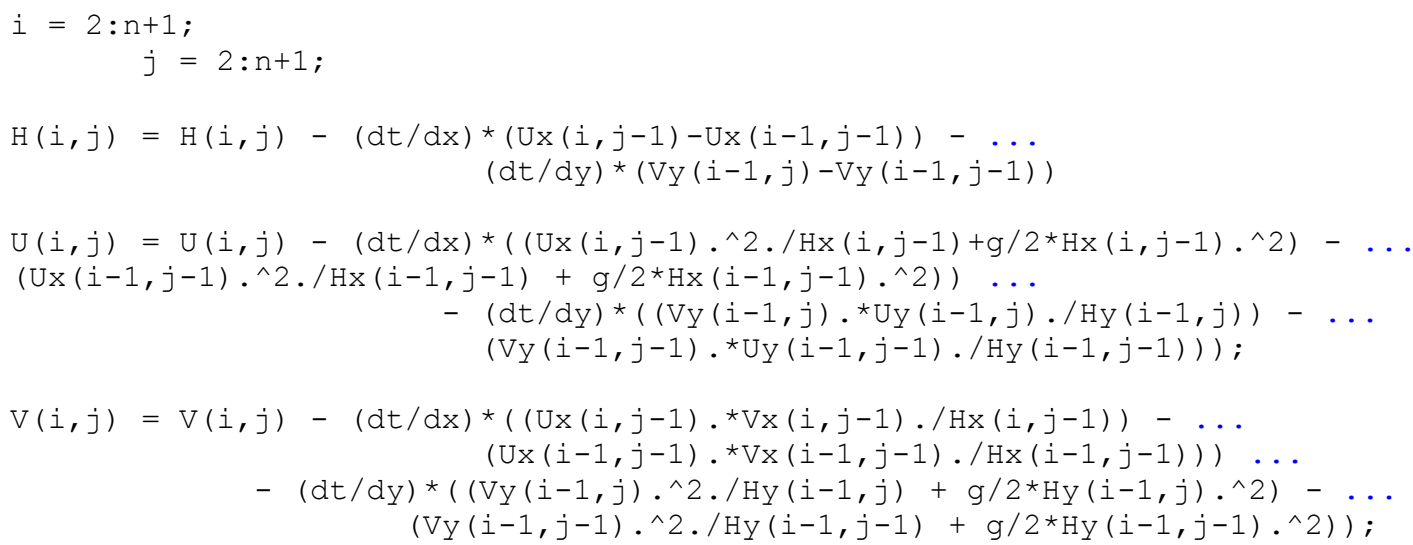

Anomali berselang non-reflektif digunakan kode seperti berikut

for $i=1: n$

if $\bmod (i, 4)==0$

$\mathrm{H}(i, 20)=1$; 
end

end

Sementara untuk anomali kedalaman dan kecepatan berselang reflektif gunakan kode

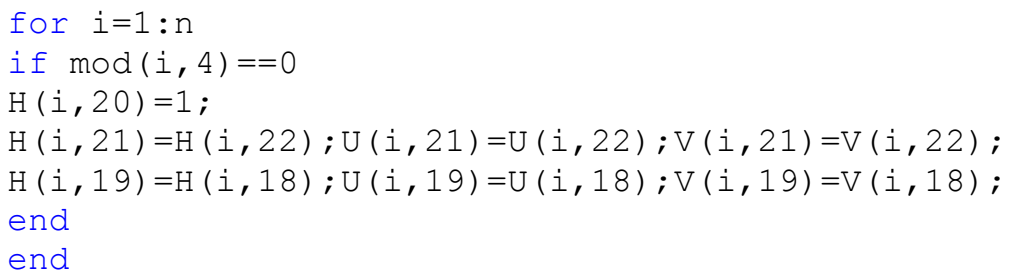

Ketiga program simulasi, baik normal, menggunakan anomali non reflektif, maupun reflektif dijalankan dalam loop hingga 11000 loop.

Untuk membandingkan pengaruh anomali antara variasi selang, nilai amplitudo gelombang di sel [1,1] dicatat selama program berjalan. Hasil yang dibandingkan adalah grafik $H$ terhadap $t$ pada sel [1,1] pada simulasi persamaan air dangkal normal (tanpa anomali kedalaman), simulasi dengan anomali sejajar (non-reflektif), dan simulasi dengan anomali sejajar reflektif

\section{Hasil dan Pembahasan}

Hasil simulasi secara visual 3D ditunjukkan pada Gambar.3. Grafik amplitudo sel $[1,1]$ selama program berjalan untuk sistem dengan anomali non reflektif dapat dilihat pada Gambar 4a. Gambar. 4b menunjukkan amplitudo sel yang sama saat sistem diberi anomali kedalaman reflektif. Dari grafik terlihat bahwa seiring berjalannya waktu, amplitudo sel menjadi relatif lebih kecil daripada sistem fisis dengan anomali normal. Perbandingan amplitudo sel [1,1] dengan hanya pemberian anomali reflektif kedalaman dan reflektif kedalaman ditambah kecepatan dapat ditunjukkan pada Gambar 4c. Gambar 4d menunjukkan perbandingan amplitudo yang sama dengan Gambar 4c, tetapi dengan menambahkan grafik amplitudo simulasi normal tanpa pemberian anomali kedalaman.

Di setiap saat grafik amplitudo sel [1,1] pada simulasi tanpa anomali (warna merah) menunjukkan selalu lebih tinggi daripada grafik simulasi dengan anomali. Pemberian syarat reflektif pada sel yang berbatasan langsung dengan anomali menjadikan amplitudo sel [1,1] lebih kecil dibandingkan dengan simulasi dengan anomali non-reflektif. Syarat tambahan berupa pemantulan kecepatan saat menimpa anomali menghasilkan amplitudo menjadi lebih kecil.

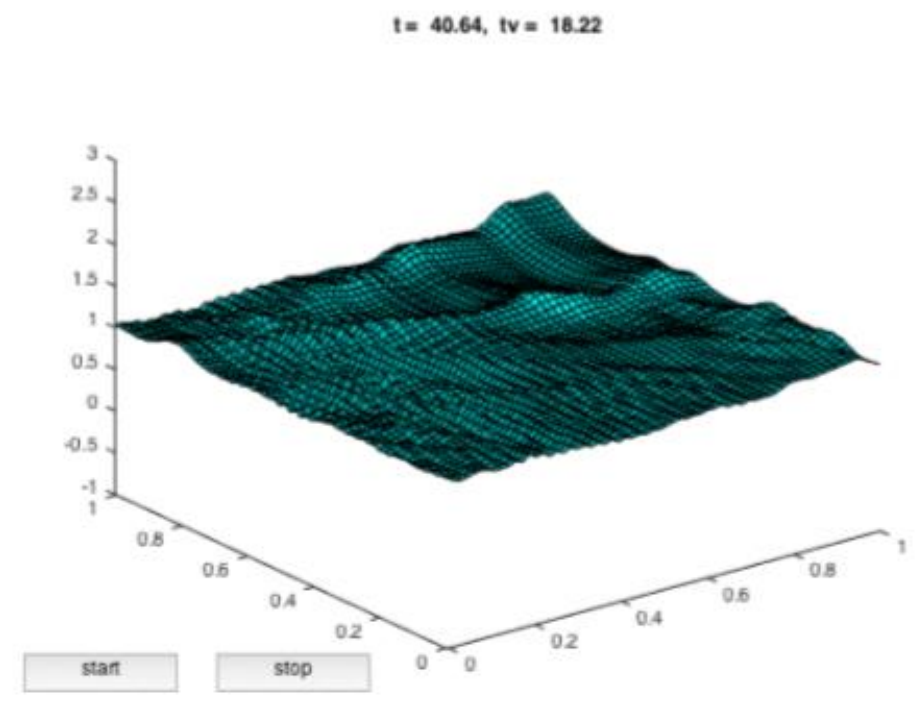

Gambar 3. Hasil simulasi 3D 


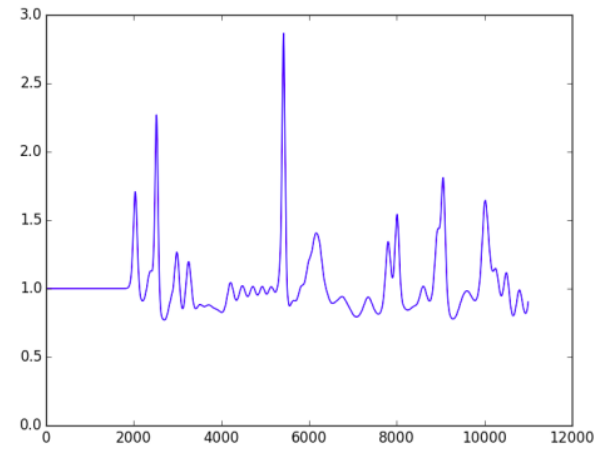

(a)

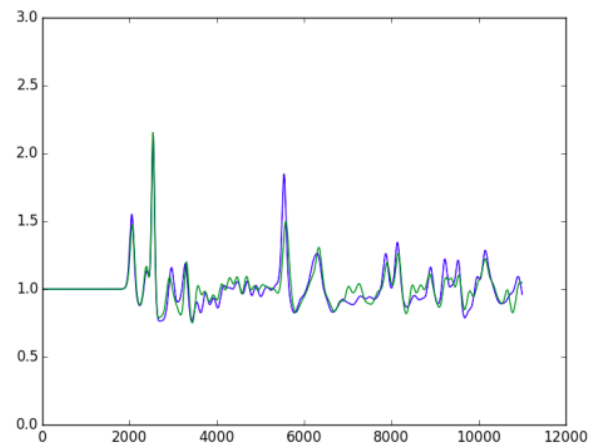

(c)

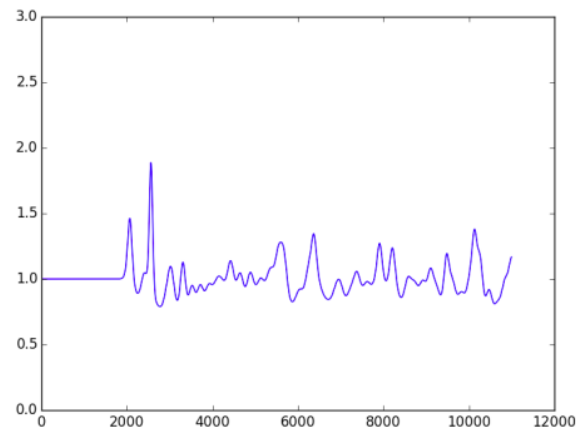

(b)

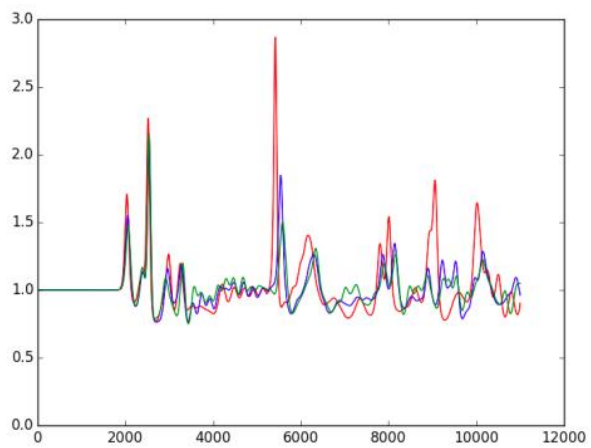

(d)

Gambar 4. Amplitudo sel [1,1] pada (a) gelombang normal, (b) anomali sejajar berselang reflektif (kecepatan dan kedalaman), (c) gabungan nilai amplitudo reflektif kedalaman saja (warna hijau) dan reflektif kedalaman+kecepatan (warna biru), (d) gabungan nilai amplitudo simulasi normal (merah), reflektif kedalaman (hijau) dan reflektif kedalaan+kecepatan (biru)

\section{Simpulan dan Saran}

Hasil simulasi menunjukkan bahwa pemberian anomali kedalaman dengan syarat reflektif kedalaman dapat mengubah arah gelombang dan menurunkan amplitudo gelombang. Syarat reflektif tambahan berupa kecepatan menurunkan amplitudo gelombang menjadi lebih kecil. Perlu penelitian lebih lanjut dengan tambahan syarat reflektif yang menyelimuti anomali sehingga menyerupai keadaan sesungguhnya.

\section{Daftar Rujukan}

[1] N. Thurey, M. Muller-Fischer, S. Schrim, M. Gross (2006). Real-time Breaking Waves for Shallow Water Simulation. Proceedings of Pacific Graphics, Maui, Hawaii, October 29-30.

[2] C. Ancey (2007). Plasticity and Geophysical Flows. J. Non-Newtonian Fluid Mech., 142, 4-35.

[3] C. Moler. "Chapter 18: Shallow Water Equations." Experiments with MATLAB. MathWorks. Web. <http://www.mathworks.com/moler/exm/chapters.html>.

[4] A. V. Tiwow, J. D. Malago (2015). Application of Navier-Stokes Equation to Laminar Fluid Flow Case in Unhorizontal Pipe. Jurnal Sainsmat, 51-56.

[5] C. R. Robinson (2011). Shallow Water Equation. Syracuse University.

[6] H. Zhang, Y. Shi, D. A. Yuen, Z. Yan, X. Yuan, dan C. Zhang (2008). Modelling and Visualization of Tsunamis. Pure and Applied Geophysics, 475-496.

[7] N. A. Pramono (2016a). Pemberian Anomali Kedalaman Reflektif pada Simulasi Persamaan Air Dangkal dengan Konfigurasi Sejajar. Prosiding Seminar Nasional Fisika Universitas Negeri Malang, Seminar Nasional Fisika dan Pembelajarannya.

[8] N. A. Pramono (2016b). Simulasi Persamaan Air Dangkal Menggunakan Persamaan NavierStokes Dengan Penambahan Anomali Kedalaman Konfigurasi Zig-Zag Sebagai Pemecah Ombak. Prosiding Seminar Nasional Fisika Universitas Negeri Malang, Seminar Nasional Fisika dan Pembelajarannya. 